ALPHA No 29 Diciembre 2009 (203-216)

ISSN 0716-4254

http://alpha.ulagos.cl

\title{
LOS MOTIVOS DEL FANTASMA: LA RELACIÓN DE CAUSALIDAD EN LOS RELATOS FANTÁSTICOS
}

The reasons of the ghost: the principle of causality in fantastic short stories

José María Martínez*

\section{Resumen}

Con frecuencia se comenta que la narrativa fantástica cuestiona y llega a desmontar los postulados de la lógica y la metafísica clásicas, y especialmente el principio de causalidad. Sin embargo, un análisis más cuidadoso de esta propuesta revela que aún son muchas las matizaciones necesarias para arribar a tal conclusión y que, incluso, podría ocurrir precisamente lo contrario; es decir, que la literatura fantástica acabase revelando el carácter perentorio de los postulados de la metafísica clásica, incluido también el principio de causalidad. Sirviéndome de algunas contribuciones del realismo filosófico contemporáneo y de la narratología de G. Prince, trato de mostrar la fragilidad de esos cuestionamientos y de postular los estrechos vínculos entre el discurso fantástico y la metafísica clásica, vínculos que, incluso, se convierten en una peculiar reivindicación del realismo aristotélico.

Palabras clave: Literatura fantástica, causalidad, metafísica, ontología.

\begin{abstract}
It is often argued that fantastic literature questions and deconstructs classic logic and classic metaphysics, including especially, the principle of causality. However, a deeper analysis of this claim reveals that there are still many issues open to discussion. Moreover, it would be even possible to affirm the opposite, i.e., that fantastic literature actually reveals the radical and mandatory nature of the classic metaphysical principles, including the principle of causality. By making use of some contributions from contemporary philosophical realism and G. Prince's narratology, I attempt to show the strong bonds that link fantastic discourse and classic metaphysics. I believe that those bonds even vindicate the consistency of Aristotelian realism.
\end{abstract}

Key words: Fantastic literature, causality, ontology, metaphysics.

A menudo se repite que la relación de causalidad es una de las correspondencias lógicas o principios metafísicos que quedaría más seriamente cuestionado por la narrativa fantástica. ${ }^{1}$ Sin embargo, los particulares

${ }^{1}$ En Borges, como se sabe, fue uno de los motivos más recurrentes (Cfr. Alazraki, 1974:113121; Cordero, 1990:189; Campra, 1985:178-80). El cuestionamiento de este principio oscila 
implicados de esta vindicación no siempre se aclaran con la debida precisión y creo, en cualquier caso, que necesitan de importantes matizaciones referidas tanto al nivel textual como al extratextual de este tipo de discursos. Las matizaciones que propongo a continuación se derivan, además, de la propia naturaleza del relato fantástico y en concreto de su hiperrealismo, es decir, de esos mecanismos de insistencia en la verosimilitud y en la historicidad de la anécdota y que, obviamente, implican el reconocimiento de un mundo mimético, de una metafísica aristotélica y realista y de una diégesis apoyada en la concatenación consecuencial de sucesos y acontecimientos (Roas, 2001:26). Acepto, de todos modos, que estas precisiones descansan en mi particular conceptualización de lo fantástico que concuerda, básicamente, con la conocida formulación de Ana M. Barrenechea, es decir, la de su definición como la coexistencia ficcional y problemática de dos niveles ontológicos y gnoseológicos diferentes.

Aunque ha sido Hume a quien tradicionalmente se le ha atribuido el cuestionamiento del principio de causalidad, los nominalistas medievales y especialmente Nicolás de Autrecort habían rechazado ya los universales y los principios globalizantes $\mathrm{y}$, por ello, habían negado de forma explícita esa relación de causalidad que ya antes habría sido cuestionada implícitamente en las doctrinas de escepticismo clásico de Pirrón. ${ }^{2}$ Después Kant, de forma involuntaria a causa de su implícito inmanentismo, y Nietzsche y el deconstruccionismo de forma más intencional, habrían continuado sus embates contra tal principio, entendiéndolo como una antropomorfización de fenómenos naturales o como un producto a posteriori del conocimiento de los efectos (Ferrater Mora, 1989:104; Nelson, 1990:XVI-XVII).

entre quienes tienden a negarlo de una forma absoluta y quienes prefieren hablar de la propuesta de unas causalidades alternativas o transgresoras. Confirmo, más bien, la segunda propuesta aunque, sobre todo, pretendo mostrar que el relato fantástico necesita y evidencia la causalidad de la metafísica aristotélica y, en particular, la operatividad de la llamada causa eficiente, es decir, el principio o agente del cambio. Para una explicación más detallada de estos conceptos, Cfr. Ferrater Mora (1989:98-102), Alvira (1982:175-215) y los apartados correspondientes indicados en Aristóteles (1998:774).

En otro orden de cosas, quiero agradecer al Faculty Research Council de la Universidad de Texas-Pan American y también al Faculty Research Council de su College of Arts and Humanities las becas que me concedieron tanto para la investigación y redacción del trabajo como para la exposición de una versión del mismo en el VI Coloquio Internacional de Literatura Fantástica (Götteborg, junio de 2007).

${ }^{2}$ De todas formas, también hay que precisar que muchas veces se ha adjudicado a Hume más de lo que realmente afirmó, pues su cuestionamiento no lo fue tanto del principio de causalidad cuanto de la posibilidad de explicitarlo en leyes científicas o universales ya que, para él, el único objeto del conocimiento serían las impresiones individuales (Cfr. Alvira, 1982:176, $\mathrm{N}^{\circ} 1$; Ferrater Mora, 1989:104). Como documenta Laverdière, el propio Hume tuvo que salir al paso de estas acusaciones ya entre sus contemporáneos (1969:244). 
Sin embargo, me convencen más las apologéticas relecturas que llevan a cabo Zubiri y algunos realistas contemporáneos. Para Xavier Zubiri, Hume habría buscado la causalidad en las impresiones, es decir, en un lugar donde no podía encontrarla, pues la causalidad sería una relación automática entre éstas del mismo modo que, sin salir del pensamiento de Hume, lo sería la relación de multiplicidad o diversidad entre esas impresiones, ya que esas impresiones - $\mathrm{y}$ en el fondo los entes reales - son causas porque, al mismo tiempo, son o tienen parte de substancia (Fowler, 1998:64-65; Ferrater Mora, 1989:100). Al igual que la multiplicidad o la diversidad, la causalidad no se identifica con las impresiones, pero debe existir, inevitablemente, para poder explicar esas y otras relaciones reales entre ellas. Por su parte, para realistas como Laverdière la causalidad sería, sobre todo, el principio metafísico inherente a la realidad del cambio o del devenir, un principio sin el cual el cambio, del tipo que sea, no puede ser explicado, ya que cambio y causa son conceptos recíprocos y autoimplicados, como pueden serlo los pares padrehijo o comprar-vender (1969:216-42). Y esto sería válido, incluso, aunque como agente del cambio se proponga el azar, pues, en este caso lo que desaparece sería sólo la regularidad de la causa, es decir, la ley, pero no la causa en sí, que en ese sentido propiamente metafísico sí sería universal (y real), aunque luego no lo fueran sus manifestaciones concretas o leyes físicas o naturales. ${ }^{3}$ Se puede decir, entonces, que la literatura fantástica no sólo no desarma el principio de causalidad, sino que, incluso, lo revela en su pureza original y metafísica, todavía limpio de concreciones materiales y específicas como lo serían las condiciones para su cumplimiento regularizable y científico. En otras palabras, el relato fantástico, aunque parece comprometer la llamada causalidad predicamental o mecanicista, lo que hace en el fondo es apuntar hacia lo que la metafísica realista denomina causalidad trascendental u ontológica, mucho más relevante que la anterior por remitir, precisamente, a una causa primera, globalizante, y, al mismo tiempo, separada del mundo físico, esencialmente distinta a él (Fabro, 1961:335-40; Richard, 1983:86). Por ello, y si todavía se quiere insistir en este punto, esa aparición de entes o fenómenos extraordinarios que ensanchan las capacidades o posibilidades de lo real no hacen sino confirmar uno de los postulados básicos de la ontología clásica, como es la distancia infinita y, por eso, siempre llena de posibilidades de nuevas apariciones ubicadas entre los entes particulares y el ser infinito y trascendental.

\footnotetext{
${ }^{3}$ Devenir implica, al mismo tiempo, los conceptos de cambio e identidad y ambos son conceptos claves en el relato fantástico. A continuación me extiendo un poco más sobre el aspecto del cambio; para el de identidad, véase mi trabajo “Subversión u oxímoron...” (2008).
} 
En todo este contexto, conviene recordar, ahora, que el devenir o cambio es el núcleo de todo discurso narrativo y, muy en particular, del relato fantástico orientado especialmente hacia la representación de un acontecimiento desacostumbrado, es decir, de un devenir insólito, de la alteración de la regularidad. Adaptando otra de las propuestas de Laverdière puede decirse que algo tan propio del relato fantástico como es la experiencia del asombro depende igualmente de la causalidad, pues si se niega este principio se negaría, también, el asombro ya que asombrarse significa precisamente desconcertarse ante lo que la mente considera inesperado o ilógico (1969:24243). Si la causa no existe, todo puede ocurrir y todo es, al mismo tiempo, aleatorio y homogéneo, y la mente del personaje y del lector no podrían asombrarse sencillamente porque todo es igualmente posible y no habrían podido crear patrones previos o leyes anteriores que hayan clasificado y uniformado la realidad a la que estaría enfrentando el nuevo acontecimiento. En el relato fantástico, el asombro se produce precisamente por lo inesperado o lo desconocido del fenómeno extraordinario, pero no porque se asuma que su causa eficiente no exista.

Así, lo que realmente ocurriría al enfrentarse con el enigma fantástico es la suspensión de la respuesta — o sea la adjudicación de una causa concreta e inmediata al fenómeno extraordinario - pero no la negación del principio de causalidad en sí; la negación se daría en el orden gnoseológico $-\mathrm{y}$ no siempre, como se verá- pero no en el óntico. Dicho de otra forma, el cuestionamiento de la lógica tradicional o aristotélica que a menudo se ha visto en este discurso puede aceptarse si se asume que el autor propone un nuevo tipo de cosmovisión con la existencia de causalidades ilógicas o transgresoras (Cortázar) o de una especie de pancausalismo donde la relación causa-efecto es universal y no particular (Borges). Sin embargo, como resulta obvio, en estas actitudes lo que se niega es la naturaleza lógica o unívoca de la causa pero no la realidad misma de la causa. Si esto se hiciera, se abandonaría el terreno de la literatura fantástica para arribar a la literatura del absurdo. Y en este sentido, la literatura fantástica es la menos absurda de las literaturas, pues precisamente su hiperrealismo implica la certeza efectiva de un hecho que acaba operando como centro gravitatorio de toda la narración y como referencia semántica clave para personajes y lectores. ${ }^{4}$ Cabe recordar, también, que según la metafísica clásica, cuanto más acto posea o más perfecta sea una causa, mayor será también su virtud operativa. Es decir, si la causa es sobrehumana o extranatural, los efectos pueden ser también sobrehumanos o

${ }^{4}$ Sobre estas interesantes divergencias entre la literatura fantástica y la detectivesca, Cfr. Rosalba Campra, "Los silencios del texto en la literatura fantástica”, 1991:56; "Fantástico y sintaxis narrativa”, 1985:106. 
extranaturales y, por eso mismo, la causa puede ubicarse fuera del alcance de la inteligencia de los personajes, del lector y también del autor; esto es, ser racionalmente inexplicable y confirmar de forma inesperada la gradación ontológica y causal propuesta por la metafísica aristotélica. ${ }^{5}$

Una segunda matización correspondería a la representación literaria de la relación causal, asunto que puede considerarse aún más espinoso que el anterior por depender del grado de fiabilidad representacional que adjudiquemos al lenguaje. Así, para una concepción inmanente o autorreferencial del lenguaje, este problema simplemente no tiene razón de ser, pues el lenguaje no comportaría ningún contenido referido al mundo externo o extramental. Pero, nuevamente, esta afirmación no está exenta de complicaciones. Por un lado, porque ya que bajo esa concepción tanto la relación o dimensión causal de los entes mentales como las operaciones lingüísticas serían actividades o productos subjetivos, cabría postular entre ambos una relación de continuidad más sólida que entre el lenguaje y la realidad extramental. De esta forma podría explicarse un tipo de continuidad ontológica que prestaría validez y coherencia a la expresión de la causalidad de las relaciones intramentales a través de unidades lingüísticas como las construcciones sintácticas consecutivas y finales, los conectores causales, etc. ${ }^{6}$ Para la concepción realista del lenguaje la solución sería más sencilla, pues el lenguaje es simplemente un espejo analógico de la realidad extralingüística, con capacidad para representar tanto entes y fenómenos aislados como las relaciones entre ellos. A favor de esta consideración cabe recordar las aseveraciones de Todorov (1975:58-74) y de Barrenechea (1972:392) respecto a que el discurso fantástico debe admitir obligatoriamente una lectura representacional y mimética del texto, en oposición a lecturas alegóricas, líricas o impresionistas orientadas más hacia esa autorreferencialidad del lenguaje.

A la vista de los trabajos sobre el tema, ${ }^{7}$ y simplificando un poco, la representación de la causalidad podría clasificarse como explícita — si la

\footnotetext{
${ }^{5}$ Por razones de espacio no aplico aquí las tipologías que la metafísica clásica hace del cambio y del devenir (ej. cambios accidentales, sustanciales, etc.) y que presumo de gran utilidad para comprender el funcionamiento del componente mimético del relato fantástico.

${ }^{6}$ Es decir, expresiones causales o finales como "porque”, "para que”, etc., podrían entenderse separadas o distintas de la realidad extramental por pertenecer a órdenes ontológicos diferentes, pero tal diferencia no sería aplicable a las realidades mentales (imágenes, impresiones, etc.) por compartir con ellas un mismo grado de realidad mental.

${ }^{7}$ Me refiero aquí a los estudios generales sobre la representación literaria de la causalidad, ya que no he podido localizar ninguno dedicado exclusivamente a la causalidad propia del relato fantástico. Mis principales referencias al respecto son los trabajos de Roy J. Nelson (1990) Brian Richardson (1997), John K. Adams (1989) y Tzvetan Todorov (1975) que recojo en la bibliografía final.
} 
causa del acontecimiento narrado se expone verbalmente como tal- o implícita, si la causa del acontecimiento se representa pero no se presenta como tal y es el contexto el que revela al lector la relación causa-efecto de los acontecimientos narrados. ${ }^{8}$ A su vez, la formulación explícita iría marcada lingüísticamente por conjunciones o expresiones causales. Un ejemplo bien conocido serían las famosas frases del primer capítulo del Quijote “y así, del poco dormir y del mucho leer se le secó el cerebro, de manera que vino a perder el juicio" (1990:37) donde tanto la causa como el efecto-consecuencia y su relación formal se hallan explícitamente verbalizadas. Un ejemplo de causalidad implícita podría ser la de "El rey burgués” — cuento de Rubén Darío- donde el poeta-vagabundo aparece muerto en el jardín sin que el narrador haya dicho expresamente que el frío del invierno haya sido el causante de su muerte, pero donde todo el contexto referencial derivado de las reglas narratológicas de la selección paradigmática de los acontecimientos apunta en esa única dirección. ${ }^{9}$ Si hiciera falta otro ejemplo clásico, puede recordarse que Shakespeare no llega a mencionar de forma explícita que las causas de las muertes de Romeo y Julieta sean respectivamente la ingestión del veneno o el autoapuñalamiento que, en sentido estricto, aparecen sólo como acciones sucesivas. ${ }^{10}$ Pero, de nuevo, dada la diégesis especificada por el autor, parecería absurdo postular una causalidad diferente o proponer que esas muertes sean sucesos espontáneos o simples construcciones mentales del lector. En este sentido, la imposibilidad de proponer una causalidad diferente, es decir, completamente subjetiva o independiente de la diégesis textual, indica la consistencia narratológica de la relación causal y, por tanto, su absoluta pertinencia en la literatura de tipo mimético-realista.

\footnotetext{
${ }^{8}$ Esta causalidad implícita no debe identificarse con la falacia post hoc ergo propter hoc con la que, a veces, se confunde. La confusión se da, sobre todo, cuando tiende a cuestionarse la validez del principio causal mediante una especie de empirismo de Hume que atribuye a la actividad receptora del lector la aparición de relaciones causales sin existencia real en el texto. (Cfr. Nelson, 1990:XIV-XXV).

9 "Y el infeliz, cubierto de nieve... tembloroso y aterido, insultado por el cierzo, bajo la blancura implacable y helada, en la noche sombría... y se quedó muerto” (Darío, 2000:161). Literalmente nos encontramos ante frases enunciativas con contenidos independientes y sin la relación de causalidad explícita del ejemplo de Cervantes. Sin embargo, a ningún lector de ese texto se le ocurre pensar que la muerte del poeta se deba, por ejemplo, a la picadura de una serpiente o a un accidente automovilístico.

${ }^{10}$ He aquí los textos: “Romeo: 'Here's to my love! [Drinks] O true apotherocary! / Thy drugs are quick. Thus with a kiss I die' [Falls]'... Juliet: 'Yea, noise? Then I'll be brief. O happy dagger! [Snatching Romeo's dagger] / This is thy sheath; there rust, and let me die. [She stabs herself and falls]; Romeo: “¡Por mi amor! -(Bebe el veneno.) ¡Oh, amigo boticario! Tus drogas son rápidas. -Así, besando, muero. (Muere)... Julieta: ¡Ruido aún! Debo apresurarme -¡Oh, dichoso puñal! (Toma el puñal de Romeo). Ésta es tu vaina; entiérrate aquí y déjame morir. (Se clava el puñal y muere). (Shakespeare, 1964:89-90. Traducción mía).
} 
En este punto resultan de especial utilidad los conceptos narratológicos de lo innarrable, lo innarrado y lo desnarrado de Gerald Prince, es decir, esas ausencias referenciales que, por razones literarias o extraliterarias, no se dan o no pueden darse en el texto. Efectivamente, lo que vemos — sobre todo en el caso de "El rey burgués" y de Romeo y Julieta - es la identidad de las causas iniciales (frío, ingestión de veneno, autoapuñalamiento) y el efecto final (muerte), pero por considerarse innecesario o no pertinente no se narra el modus operandi específico de esas causas ni la concatenación de causas y de efectos intermedios que llevan al efecto final. ${ }^{11}$ Es en este mismo grupo de modalidades narratológicas donde tendríamos que ubicar, entonces, la expresión de la causalidad fantástica que normalmente sugiere o identifica la causa inicial y el efecto final, pero no la concatenación de hechos que une estos extremos. La diferencia, obviamente, es que esa serie intermedia de causas, efectos, concatenaciones y condiciones se da por asumida o conocida en la narración realista, porque el mundo representado se identifica con el mundo del lector. En la fantástica, sin embargo, todo ello queda en suspenso porque, precisamente, el relato se abre a la posibilidad de un mundo diferente al del lector y al de los personajes que le resultan homólogos. Pero, de nuevo, esto no es lo mismo que negar la existencia de una causa inicial o, por tanto, negar la relación de causalidad.

Estas dos representaciones lingüísticas de la causalidad —la explícita y la implícita- aparecen tanto en el discurso mimético-realista como en el nivel mimético del discurso fantástico. Pero este segundo discurso cuenta lógicamente con la obligación de una causalidad implícita diferente, sin manifestación verbal posible, pues esa ausencia se corresponde con su presentación del enigma como algo inexplicable, sin causa concreta conocida y, por tanto, sin ser expresión lingüística correspondiente. Su verbalización

\footnotetext{
${ }^{11}$ En el caso de Don Quijote la situación es análoga. La principal diferencia estriba en que la presencia explícitamente textual de los conectores causales evita esa impresión de fragmentación de las acciones que se da en la diégesis con causalidad implícita y que deja más al descubierto los vacíos donde se ubica la serie de causas y efectos intermedios que unen ambos extremos. Resulta obvio, entonces, que desde el punto de vista práctico, la única causalidad estrictamente viable es la implícita, pues el narrador no tiene la posibilidad de narrar la totalidad absoluta de los factores que intervendrían a cada momento en cada anécdota, ni la infinita concatenación de causas y efectos que unirían el acontecimiento más mínimo a toda la dinámica del universo, como ya recordaba Borges (Alazraki, 1974:114). La narración es siempre un proceso de selección paradigmática que funciona por eliminación — voluntaria y forzada- de elementos no pertinentes que no aparecen narrados pero cuya participación en la anécdota está siempre latente. La narración de la más mínima anécdota funciona siempre así y una representación totalizante sería imposible porque, al final, su conexión con el resto del universo implicaría la representación de éste y, por tanto, la reducción de todas las anécdotas posibles a una sola.
} 
implicaría la revelación del origen o de los caminos del cambio y en consecuencia, la desaparición de la incógnita. Y aquí, de nuevo, volvemos a la capacidad representacional del lenguaje. Ya que tenemos la verbalización de la causa inicial y del efecto final, ¿Cómo entender entonces la imposibilidad de representación de las causas y efectos intermedios? ¿No existen éstos porque no pueden ser verbalizados o no pueden ser verbalizados porque la capacidad representacional del lenguaje sólo alcanza a los mundos conocidos por el autor o por los personajes? En el caso del discurso fantástico me inclino por la segunda opción, pues es la única manera de explicar la efectividad del acontecimiento extraordinario, su realidad histórica.

Para ejemplificar esto y mostrar de paso que el relato fantástico necesita o contiene también la casualidad explícita —es decir, aquella que tanto se dice que cuestiona- quizá nada mejor que recordar la frase inicial de “Tlön, Uqbar, Orbis Tertius”, uno de los relatos de Borges escrito, precisamente, como alternativa al mundo aristotélico. La narración comienza así: "Debo a la conjunción de un espejo y de una enciclopedia el descubrimiento de Uqbar” (1987:113). Esa acción o coincidencia inicial —la causa o arké que menciona Richard (1983:85) — es lo que pone en marcha un encadenamiento consecuencial de hechos en una relación casi continua de causa-efecto explícita o implícita-realista hasta el momento de la aparición de los objetos procedentes de Tlön. En el contexto del relato estos objetos explicarían su origen a partir de la existencia del nuevo mundo, aunque el modo de llegada hasta el mundo mimético u ordinario no se revele, porque no se conocen las condiciones para que se produzca esa llegada. Es decir, la causa se revela, pero no las condiciones, porque éstas son las que concretan la ley. ${ }^{12}$ Pero si en el relato de Borges cabría la remota posibilidad de pensar en otra causa primera diferente a Tlön — por no aparecer textualmente explícita— no ocurre así, por ejemplo, en "Ridder y el pisapapeles", de Julio Ramón Ribeyro, donde la causa de la aparición del pisapapeles en un lugar y en un tiempo ilógicos queda revelada por la declaración final del protagonista privilegiado, aunque éste no descubra las condiciones para que esa causa haya producido el efecto final

-Pero ¿Cómo vino a parar aquí?

Ridder sonrió esta vez: -Usted lo arrojó (1998:281)

\footnotetext{
${ }^{12}$ La condición no ha de identificarse con la causa, pues aquélla es el "requisito o la disposición necesaria para el ejercicio de la causalidad, algo meramente auxiliar que hace posible o impide la acción de la causa, pero la condición en cuanto tal no posee la causalidad” (Alvira, 1982:187).
} 
Obviamente, no siempre ocurre de esta manera $\mathrm{y}$, a veces, la causa concreta queda oculta o se presenta en su ambigüedad, como en el caso de "La prima Rosa”, de José María Merino (2002) donde las heridas de la muchacha pueden, en principio, haberse debido al anzuelo del protagonista o al arbusto donde ella dice haberse enredado. Pero, de nuevo, la imposibilidad de asignar una causa concreta a ese efecto no significa que ésta no exista, sino que ésta no se conoce y, aún así, ese desconocimiento no siempre es total, pues a menudo al menos uno de los protagonistas posee la clave para descifrar la incógnita, aunque ese desciframiento no puedan llevar a cabo ni el lector ni el resto de los personajes. Estos, sencillamente, permanecen en un nivel infrasciente, por debajo del suprasciente que puede ocupar algún personaje privilegiado, como sería el caso de Rosa del relato de José M. Merino, y que sí tendría acceso al conocimiento de la relación causal oculta a los demás. Volviendo a Ribeyro, su relato es especialmente útil para lo que aquí trato de mostrar, porque, curiosa o necesariamente, lo que en él queda cuestionado es la ambigüedad o fluidez de los parámetros espaciotemporales, pero no la noción de causalidad, que viene exigida por la sintaxis narrativa para poder completar la anécdota y convertirse en un texto inteligible. En este caso es, precisamente, la revelación explícita de la causalidad la que sustenta la posibilidad de plantear el enigma.

Así, pues, en la literatura realista todos los elementos causales y consecuenciales son conocidos o asumidos porque no puede quedar hueco para el enigma. Su universo es cerrado, la causalidad continua y el narrador es dueño completo del mundo que ha creado. La causa inicial y el efecto final siempre aparecen narrados por ser la manera estructural de garantizar la continuidad de la anécdota. Esto no se identifica necesariamente con una disposición lineal y diacrónica pues, a veces, la causa sólo aparece $a$ posteriori, ${ }^{13}$ aunque, de hecho, en la diégesis real la causa haya sido anterior al efecto. El único vacío narratológico posible es el de la concatenación asumida, por tratarse de algo no pertinente para la narración (el modus operandi del veneno en Romeo y Julieta, por ejemplo). De la misma forma, la causa final, es decir, el motivo ulterior de ese momento, se considera abierto o plural en el relato realista porque en él caben muchas variaciones intencionales. Por el contrario, en el relato fantástico la conclusión de ese acontecimiento siempre se restringe a los efectos propios del relato fantástico, como son la duda, el asombro, el terror, etc., sin dejar lugar para otros que materialicen una purificación catártica, como puede ser el sentimiento de felicidad, el reencuentro, etc. Este momento ulterior puede, a su vez,

${ }^{13}$ Un ejemplo típico es el de las novelas detectivescas que suelen desentrañar al final el móvil o arké de toda la anécdota. 
identificarse con la causa final de la metafísica clásica y, así visto, sería otra de las divergencias causales entre los dos tipos de literatura.

En el relato fantástico la concatenación intermedia siempre está narratológicamente ausente, pero no así la causa inicial y el efecto final, pues estructuralmente - y por ello narratológicamente- siempre hacen falta dos elementos para establecer una relación. Pero, en este caso, la relación no puede definirse en sus pormenores por la presencia de esa concatenación intermedia desconocida que sería la incógnita de la ecuación. Por su lado, la causa inicial puede ser, en este caso, real o sugerida, pero, en ambos casos, es narratológicamente necesaria por esa misma razón, porque sólo así pueden el lector y los personajes relacionar el efecto con algo externo a él mismo y formular consecuentemente una ecuación en la que, de nuevo, aparece de forma obligatoria la incógnita de la concatenación intermedia. En el caso de la causa inicial conocida o explícita "Ridder y el pisapapeles" la incógnita es el modo concreto de la operación de la causa inicial. En el segundo caso "La prima Rosa”, de Merino o "Lanchitas”, de Roa Bárcena (2003) es, más bien, la indefinición de la efectividad de la causa sugerida, pues ésta no se presenta como cierta sino como posible. El enigma aquí parte de la identidad real de la causa inicial y no tanto en su modus operandi; al no poder identificar la primera, el segundo, la concatenación subsiguiente, tampoco es narratológicamente viable.

Quedaría por comentar la matización referida al nivel intermedio entre lo textual y lo extratextual, es decir, el nivel del lector o de la recepción del texto. Para confirmar los vínculos de la causalidad con este nivel puede recordarse, sencillamente, la nomenclatura inglesa para la teoría de la recepción, como la teoría del reader-response, donde obviamente la reacción del lector está causada o es el efecto de su percepción o de su interpretación del texto y éste, a su vez, es la causa desencadenante de esa reacción. Si toda literatura persigue un fin e, incluso, puede asegurarse que, en un sentido amplio, la intención provocativa o apelativa del texto es anterior a su intención informativa (Luján, 2001:16), esto resulta especialmente claro en la literatura fantástica que persigue, sobre todo, la sorpresa del lector mediante la presentación de lo inesperado y el consiguiente cuestionamiento del propio mundo extraliterario y normativo del lector. Cualquiera que sea el caso, esa reacción ante el hecho fantástico funciona como efecto de la realidad de lo extraordinario y alcanza un lugar tan preeminente en la fisonomía de este tipo de relatos que no resulta extraño que, a menudo, éstos se hayan explicado en función de ese efecto, sea éste el terror (Caillois, 1967) la duda (Todorov, 1975:24-40) o la desestabilización existencial (Roas, 2001:197). En este sentido, puede afirmarse que si la anécdota del relato fantástico no consigue despertar la extrañeza del lector — es decir, si no funciona como causa 
efectiva de una reacción extratextual concreta- la narración se convierte en un fracaso y dejaría en entredicho su adscripción al género o modo de lo fantástico. De esta forma, la causalidad se encuentra, también, en el núcleo pragmático del discurso fantástico.

No cuento aquí con el espacio suficiente para relacionar con el principio de causalidad los variados recursos de verosimilitud y de acercamiento al lector empleados por los narradores de lo fantástico, pero sí quiero comentar muy brevemente uno de ellos, como es la pretendida historicidad del relato y que, por otra parte, Borges logra mostrar tan magistralmente en "Tlön, Uqbar, Orbis Tertius". En estos casos, el relato se convertiría en un documento real de un hecho también real que ubicaría la anécdota y la secuencia de causas y efectos no sólo en el mundo mimético del texto sino, también, en el histórico y biográfico que compartirían autor y lector. En este tipo de relatos, el grado de identificación entre lector, personajes y anécdota sería de un grado mayor por ubicarse todos ellos en el nivel extratextual de lo histórico y lo biográfico. En consecuencia, el efecto perturbador del acontecimiento inesperado sería, también, más intenso que en otro tipo de relatos fantásticos, porque la presencia de la irrealidad ofrecida en los vacíos narratológicos correspondientes resultaría para el lector más cercana, intensa y amenazante.

Algo semejante puede decirse de un hecho análogo a la lectura histórica como lo es el de la recepción intradiegética que todos o, al menos, alguno de los personajes hacen del fenómeno extraordinario. ${ }^{14}$ Es decir, el principio de causalidad se revela, también, en la continuidad que existe entre la percepción de lo inexplicable por parte de los personajes y su reacción subsiguiente, sea ésta el terror, la duda, la sorpresa o el desconcierto. Lo que suele representarse de dos maneras. En relatos como "La prima Rosa" o "Ridder y el pisapapeles" la presentación del enigma se da al final de la narración, dejándola en suspenso, sin posteriores explicaciones. En otras ocasiones — como en "Lanchitas”, de Roa Bárcena- el momento climático se da en medio de la narración, luego de lo cual el lector asiste a la descripción de los frustrados intentos de desciframiento y a la consiguiente perplejidad por parte de los personajes. La identificación del lector con ellos no es tan inmediata como en el primer caso porque la representación de esas reacciones por parte del narrador hace que el lector regrese a la anécdota y deje de estar a solas con el enigma, como a solas se quedaban también los

\footnotetext{
${ }^{14}$ Esta reacción de los personajes vista como efecto de la experiencia de lo extraordinario es, también, un elemento de gran riqueza narratológica y complejidad argumental, a la que me refiero sucintamente pero que exige una atención que, por cuestión de espacio, no puedo darle aquí.
} 
protagonistas de relatos como "La prima Rosa” o "Ridder y el pisapapeles". Pero, en cualquier caso, esa continuación de la anécdota tras la aparición del enigma sólo puede explicarse como una consecuencia o efecto del mismo y esas reacciones de los personajes y el lector como una consecuencia de su encuentro con lo desconocido.

Cabe resumir, pues, que el relato fantástico se aleja del mimético realista tradicional cuando en un momento de la diégesis la causa específica o, sobre todo, las condiciones en que ésta actúa quedan obligatoriamente ocultas al lector y a alguno o a todos los personajes. Pero, al mismo tiempo, la presencia del efecto o de un acontecimiento nuevo en el mundo natural, por muy fantásticos que sean, no puede implicar la negación del principio de causalidad, pues, este principio es siempre inherente a todo cambio y, precisamente, el cambio - la aparición de lo no obvio - es la materia esencial del discurso narrativo y, especialmente, del fantástico. En este sentido, la causalidad se presenta como una necesidad sintagmática del relato fantástico, pues, como explica Adams refiriéndose a todo tipo de discurso narrativo (1989: 149) la causalidad opera en una narración —que es al mismo tiempo una explicación- como el principio de selección paradigmática, que hace relacionar a un acontecimiento concreto con otro también concreto y específico, elegido entre otros muchos posibles. Quizá, con la excepción del relato policiaco, pocos géneros como el fantástico desarrollan de forma tan preeminente la secuencia causa-efecto en el desarrollo de la anécdota. En sus relatos, todos los momentos y escenas particulares, todas las selecciones paradigmáticas y recursos retóricos, se hallan encaminados y en dependencia del efecto final. La posibilidad de la metalectura de la que hablaba Todorov —y lo que también Todorov llamó pandeterminismo - confirma, también, el mecanicismo de estos relatos (1975:58-74;110-13) porque, en el fondo, estas narraciones están construidas siempre de una manera minuciosa y en una continua concatenación de causas y efectos o acciones y consecuencias que se suspende únicamente, y de modo relativo, en el momento del enigma. Lo que sí se da de forma inevitable es la ausencia verbal de causas y efectos intermedios, pero esto es, en el fondo, sólo un cuestionamiento de la regularidad de unas leyes particulares derivadas de ese principio general y metafísico. $\mathrm{Y}$ es que el nivel mimético de los relatos fantásticos es un mundo abierto (Nicolajeva, 1988:36) en contacto con otros mundos con leyes diferentes o desconocidas, pero que, precisamente, revelan su existencia mediante su interacción con ese nivel ordinario. Y esa interacción puntual procedente del mundo extraordinario es, simplemente, una forma de movimiento o de cambio que, de nuevo, no hace sino explicitar el principio de causalidad. Y es que el fantasma también tiene sus motivos para hacerse cotidiano. 
Los motivos del fantasma: La relación de causalidad en los relatos fantásticos

The University of Texas-Pan American*

Department of Modern Languages and Literature

1201 W. University Drive, CAS 320

Edinburg, Texas, 78539 (EE.UU.)

jmmartinez@utpa.edu

\section{BIBLIOGRAFÍA}

ADAMS, John K. "Causality and Narrative", en Journal of Literary Semantics. 18:3 (1989):149-62.

ALAZRAKI, Jaime. La prosa narrativa de Borges. Temas. Estilo. Madrid, Gredos, 1974.

ALVIRA, Tomás, et al. Metafísica. Pamplona. EUNSA, 1982.

ARISTÓTELES. Metafísica (Ed.). Valentín García Yebra. $2^{\mathrm{a}}$ ed. Madrid: Gredos, 1998.

BARRENECHEA, Ana María. "Ensayo de una tipología de la literatura fantástica (A propósito de la literatura hispanoamericana)”, en Revista Iberoamericana 38:80 (1972):391-403.

BORGES, Jorge Luis., et al (Eds.). Antología de la literatura fantástica. Buenos Aires: Hermes, 1987.

CAILLOIS, Roger. Introducción a Antología del cuento fantástico. Buenos Aires: Sudamericana (1967):7-19.

CAMPRA, Rosalba. “Lo fantástico: una isotopía de la trasgresión”, en Teorías de lo fantástico (Ed.). David Roas. Madrid: Arco (2001):153-91.

------- "Los silencios del texto en la literatura fantástica”, en El relato fantástico en España e Hispanoamérica. (Ed.) Enriqueta Morillas Ventura. Madrid: Quinto Centenario/Siruela (1991):49-73.

------- Fantástico y sintaxis narrativa. Río de la Plata 1 (1985):95-111.

CERVANTES, Miguel de. Don Quijote de la Mancha (Ed.). Martín de Riquer. 12a ed. Barcelona: Juventud, 1990.

CORDERO, Sergio. "Filosofía y lingüística en los cuentos fantásticos de Jorge Luis Borges”, en La Palabra y el Hombre: Revista de la Universidad Veracruzana, 74 (1990):189-194.

DARÍO, Rubén. Azul... Cantos de vida y esperanza (Ed.). José María Martínez. $3^{\text {a }}$ ed. Madrid: Cátedra, 2000.

FABRO, Cornelio. Participation et causalité selon S. Thomas d'Aquin. Louvain: Publications Universitaires, 1961.

FERRATER MORA, José. Diccionario de filosofía de bolsillo. 2 Vols. Madrid: Alianza, 1989. 
FOWLER, Thomas B. "The Formality of Reality: Xavier Zubiri's Critique of Hume's Analysis of Causality”, en The Xavier Zubiri Review 1 (1998):57-66.

LAVERDIÈRE, Raymond. Le principe de causalité. Recherches thomistes récentes. París: Librairie Philosophique J. Vrin, 1969.

LUJÁN ATIENZA, Ángel Luis. “Tema y efectos: semántica y pragmática en el comentario de textos poéticos”, en Revista de Literatura 63:125 (2001):5-20.

MARTÍNEZ, José María. “Subversion or oxymoron?: Fantastic Literature and the Metaphysics of the Object", en Neophilologus 92:3 (2008):367384.

MERINO, José María. “La prima Rosa”, en Antología. Los mejores relatos fantásticos de habla hispana (Ed.). Joan Estruch i Tobella. $6^{\mathrm{a}}$ ed. Madrid: Alfaguara (2002):91-101.

NELSON, Roy J. Causality and Narrative in French Fiction from Zola to Robbe-Grillet. Columbus: Ohio University Press, 1990.

NICOLAJEVA, Maria. The Magic Code. The Use of Magical Patterns in Fantasy for Children, n. p., Almqvist and Wiksell International, 1988.

PRINCE, Gerald. “The Disnarrated”, en Style 22:1 (1988):1-8.

RIBEYRO, Julio Ramón. Cuentos completos. Madrid: Alfaguara, 1998.

RICHARD, Claude. "Causality and Mimesis in Contemporary Fiction”, en SubStance 12:3 (1983):84-93.

RICHARDSON, Brian. Unlikely Stories. Newark: University of Delaware Press, 1997.

ROA BÁRCENA, José María. "Lanchitas”, en Antología del cuento fantástico hispanoamericano del siglo XIX (Ed.). José Javier Fuente del Pilar. Madrid: Miraguano (2003):43-56.

ROAS, David (comp.). Teorías de lo fantástico. Madrid: Arco, 2001.

SHAKESPEARE, William. Six Plays (Ed.). Charles J. Hill. Boston: Houghton Mifflin Company, 1964.

TODOROV, Tzvetan. The Poetics of Prose. Trad. Richard Howard. Ithaca: Cornell University Press, 1977 (Originalmente La Poétique de la prose. Paris: Seuil, 1971).

------- The Fantastic. A Structural Approach to a Literary Genre. Ithaca: Cornell University Press, 1975 (Originalmente Introduction à la littérature fantastique. Paris: Seuil, 1970). 